\title{
A new species of terrestrial planarian of the genus Notogynaphallia Ogren \& Kawakatsu (Platyhelminthes, Tricladida, Terricola) from south Brazil and some comments on the genus
}

\author{
Eudóxia Maria Froehlich ${ }^{1} \&$ Ana Maria Leal-Zanchet ${ }^{2}$
}

\author{
${ }^{1}$ Departamento de Zoologia, Universidade de São Paulo. Rua do Matão, Travessa 14, 321, Cidade Universitária, 05508-900 \\ São Paulo, São Paulo, Brasil. \\ 2 Instituto de Pesquisas de Planárias, Centro de Ciências da Saúde, Universidade do Vale do Rio dos Sinos. 93022-000 São \\ Leopoldo, Rio Grande do Sul, Brasil. E-mail: ipp@cirrus.unisinos.br
}

\begin{abstract}
A new species of Notogynaphallia Ogren \& Kawakatsu, 1990, from Southern Brazil, is described. Notogynaphallia ceciliae sp. nov. has an elongated body with parallel margins and five dorsal dark longitudinal stripes on a yellowish ground. It possess branched efferent ducts, each branch opening separately into the anterior and median thirds of the long prostatic vesicle. Comparative commentaries on the most important characters of the external and internal morphology of the 23 species of the genus are also presented, so delimiting smaller inside groups.
\end{abstract}

KEY WORDS. Geoplaninae, morphology, species complex, taxonomy.

In a previous paper a complex of four species of Notogynaphallia Ogren \& Kawakatsu, 1990 (Geoplanidae , Geoplaninae Stimpson, 1857) was presented; all the species showing elongated body, with parallel margins and dorsum with five or seven dark longitudinal stripes on a yellowish background (LEAL-ZANCHET \& Froenlich 2001). In the present paper, Notogynaphallia ceciliae sp. nov., one of the three species of the complex occurring in the National Forest of São Francisco de Paula (Leal-Zanchet \& CARbayo 2000), is described. In addition, as it showed necessary, a previous brief comparative revision of the most important morphological characteristics of the 23 species assigned to Notogynaphallia by the original authors, so delimiting some smaller intra-generic groups, is also presented.

\section{MATERIAL AND METHODS}

Specimens of Notogynaphallia were collected in the National Forest of São Francisco de Paula, state of Rio Grande do Sul, located between, $29^{\circ} 23^{\prime}$ and $29^{\circ} 27^{\prime} \mathrm{S}$, and $50^{\circ} 23^{\prime}$ and $50^{\circ} 25^{\prime} \mathrm{W}$, at an altitude of $\sim 930 \mathrm{~m}$. Live specimens were brought to the laboratory to describe the external morphology and colour pattern. Following, the worms were killed using boiling water and fixed with Lillie's neutral $4 \%$ formaline solution (RomeIs 1989). Fragments of the anterior region, pre-pharyngeal region in one or two fragments, pharynx, and copulatory apparatus were dehydrated in ascending ethanol series, treated with isopropanol, and embedded in Paraplast Plus (Sigma). Serial sections, $6 \mu \mathrm{m}$ thick, were stained with Goldner's Masson or Cason's Mallory (RomeIs 1989). To obtain better staining reactions, dewaxed sections were submitted to mordanting with SUSA's fixative (RomeIs 1989) for 20 hours.

The ratio of the height of the cutaneous musculature to the height of the body (mc:h index in Froenlich 1955) was determined in the median region of a transversal section of the pre-pharyngeal region. Mesenchymatic muscle fibers were counted in transversal sections of the same region. Colour descritors, based on the uptake of dyes of particular colours, were used for classifying secretions with trichrome methods: erythrophil (red-loving), xanthophil (orange-loving) and cyanophil (dark blue-loving). The term cyanophil also applies to secretions which have an affinity for the green dye of Goldner's Masson.

For comparison, slides of pharynx and copulatory apparatus of Notogynaphallia caissara (E.M. Froehlich, 1955), N. muelleri (Diesing, 1861) and N. fita (Froehlich, 1959) of the Land Planarians Scientific Collection of E.M. Froehlich were studied. Specimens and type material have been deposited in the following reference collections: Museu de Zoologia da Universidade do Vale do Rio dos Sinos (MZU), São Leopoldo, Rio Grande do Sul, Brazil, and the Helminthological Collection of Museu de Zoologia da Universidade de São Paulo (MZUSP), São Paulo, São Paulo State, Brazil. 


\section{Notogynaphallia Ogren \& Kawakatsu, 1990}

\section{Notogynaphallia ceciliae sp. nov.}

Notogynaphallia sp. 1; Leal-Zanchet \& Carbayo, 2000; LealZanchet \& Froehlich, 2001

Notogynaphallia sp. 3; Carbayo, Leal-Zanchet \& Vieira, 2001

Notogynaphallia sp. 2; Carbayo, Leal-Zanchet \& Vieira, 2002

Etymology. This species is named after Maria Cecília Braun who made the first collections of land flatworms in the Instituto de Pesquisas de Planárias (IPP) and dedicated some years to study this material.

Type material. Holotype: MZUSP PL.150: M. Cardoso, leg. 11.XII.1997 - pre-pharyngeal region: transversal sections on eight slides; pharynx: sagittal sections on 11 slides; copulatory apparatus: sagittal sections on 11 slides. Paratypes: MZUSP PL.151: S.A. Souza, leg. 25.XI.1998 - anterior region at the level of the ovaries: sagittal sections on 18 slides; pre-pharyngeal region in two fragments: transversal sections on 16 slides; pharynx: sagittal sections on 17 slides; copulatory apparatus: sagittal sections on 18 slides; MZUSP PL.152: M. Cardoso, leg. 14.V.1999 - preserved in ethanol 70 ${ }^{\circ}$ MZU PL.00027: L. Teixeira, leg. 08.VI.1998 - preserved in ethanol $70^{\circ}$; MZU PL.00028: M. Cardoso, leg. 31.VII.1998 - pre-pharyngeal region: transversal sections on 4 slides; pharynx: sagittal sections on seven slides; copulatory apparatus: sagittal sections on nine slides; MZU PL.00029: M. Cardoso, leg. 16.XII.1998 - anterior region at the level of the ovaries: sagittal sections on 16 slides; pre-pharyngeal region: transversal sections on seven slides; pharynx: horizontal sections on six slides; copulatory apparatus: horizontal sections on 33 slides.

Type-locality. São Francisco de Paula, state of Rio Grande do Sul (RS), Brazil, in areas of native ombrophilous forest with and without Araucaria angustifolia (Bert.) Kuntze and in an area of reforestation with Pinus elliottii Engelm. - Brazil.

Distribution. Rio Grande do Sul (São Francisco de Paula)

Diagnosis. Dorsum yellowish with five dark brown longitudinal stripes; median stripe thin but very distinct; paramedian and lateral stripes with interposed pigment spots; wide marginal zone, free of stripes; eyes dorsal, without clear halos; glandular margin absent; mc:h, 14-17\%; pharynx bell-shaped with folded margins; the most anterior testes posterior to ovaries, the most posterior ones lateral to the pharynx; branched efferent ducts, each branch opening separately into anterior or median third of prostatic vesicle; extrabulbar prostatic vesicle long, laterally sinuous, with proximal portion forked exceeding the posterior end of pharyngeal pouch; male atrium very long, highly folded, with histologically differentiated proximal wall; oviducts emerging from dorsal side of the median third of ovaries, and ascending immediately after the gonopore; common glandular oviduct dorsal to the female atrium; vagina curved dorso-anteriorly; female atrium, ample and folded; length of the male atrium, 4.0 to 6.0 times that of the female one.

Description. External morphology: body elongated with parallel margins, anterior tip obtuse and posterior tip pointed (Fig. 1). When crawling, the maximal length reaches $63 \mathrm{~mm}$ (Tab. I). The distance from the mouth and the gonopore to the anterior tip varies from $54 \%$ to $61 \%$ and $66 \%$ to $78 \%$ of the

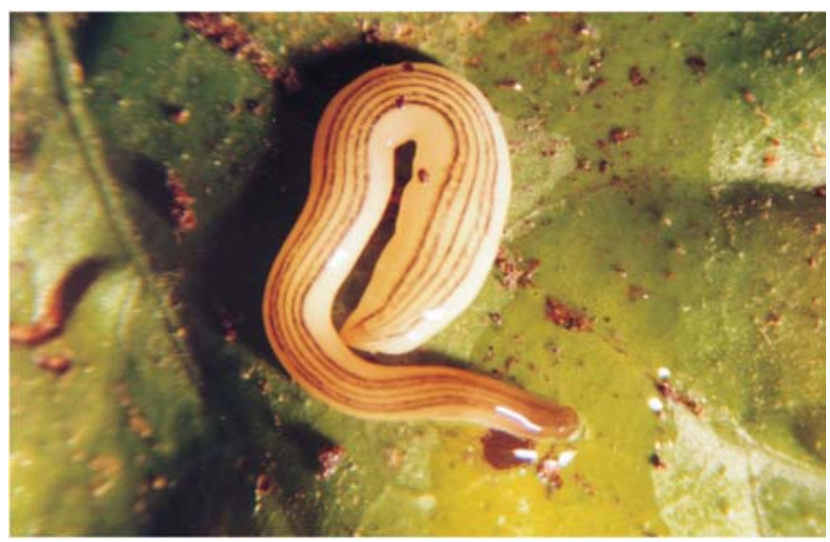

Figure 1. Notogynaphallia ceciliae sp. nov.: photograph of live specimen (length of $23 \mathrm{~mm}$ at rest) in dorsal view. Some grains of sand are seen over the dorsal surface.

body length, respectively (Tab. I). Dorsal ground colour yellowish, ventral one whitish. Living specimens show an orange anterior tip dorsally and ventrally. Over the dorsal ground colour there are five dark brown longitudinal stripes, one median, two paramedian, and two lateral (Figs 1,2 ). In paratype MZUSP PL.152, median stripe begins at $2 \mathrm{~mm}$ from the anterior tip (ca. $8 \%$ of the body length), the lateral ones at $1.5 \mathrm{~mm}$ (ca. 6\% of the body length). Paramedian stripes first appear as pigment spots convergent with the lateral stripes, at approximately $2.5 \mathrm{~mm}$ from the anterior tip. The five stripes extend up to ca. $0.8 \mathrm{~mm}$ from the posterior end (ca. $97 \%$ of the body length), becoming convergent without meeting. Lateral stripes at $0.6 \mathrm{~mm}$ from the body margins (one-quarter of body width), thus leaving a wide marginal zone free of stripes. Median stripe thinner $(0.03 \mathrm{~mm}$ or $1 / 80$ of the body width), being the most distinct and darkest. Paramedian stripes constituted of small pigment spots, several times discontinued. Lateral stripes $(0.1$ $\mathrm{mm}$ or $1 / 24$ of the body width) continuous and better defined than the paramedian. Pigment spots often interposed between the paramedian and the lateral stripes (Fig. 2). Eyes initially marginal and uniserial, contouring anterior tip. In paratype MZUSP PL.152, they become pluriserial after reaching $3.6 \mathrm{~mm}$ from anterior tip (ca. 14\% of body length) and spread up to near the lateral stripes (Fig. 2). After approx. $11.5 \mathrm{~mm}$ from anterior tip (ca. $44 \%$ of body length), eyes become scattered and limited to body margins, occurring up to posterior end. No clear halos.

Epidermis and musculature at the pre-pharyngeal region. Creeping sole $75 \%$ to $85 \%$ (Fig. 3, Tab. I). Dorsal epidermis and body margins with openings of three types of secretory cells: (1) cells with a coarse erythrophil secretion, the most abundant; (2) cells with a cyanophil amorphous secretion; and (3) rabdithogen cells. Creeping sole with abundant secretory cells with cyanophil amorphous secretion, numerous cells with fine erythrophil secretion, and few rabdithogen cells. No glandular margin.

Cutaneous musculature well developed (Tab. II). It is higher ventrally than dorsally, $110 \mathrm{~mm}$ and $74 \mathrm{~mm}$, respectively, in the median region of a transversal pre-pharyngeal 


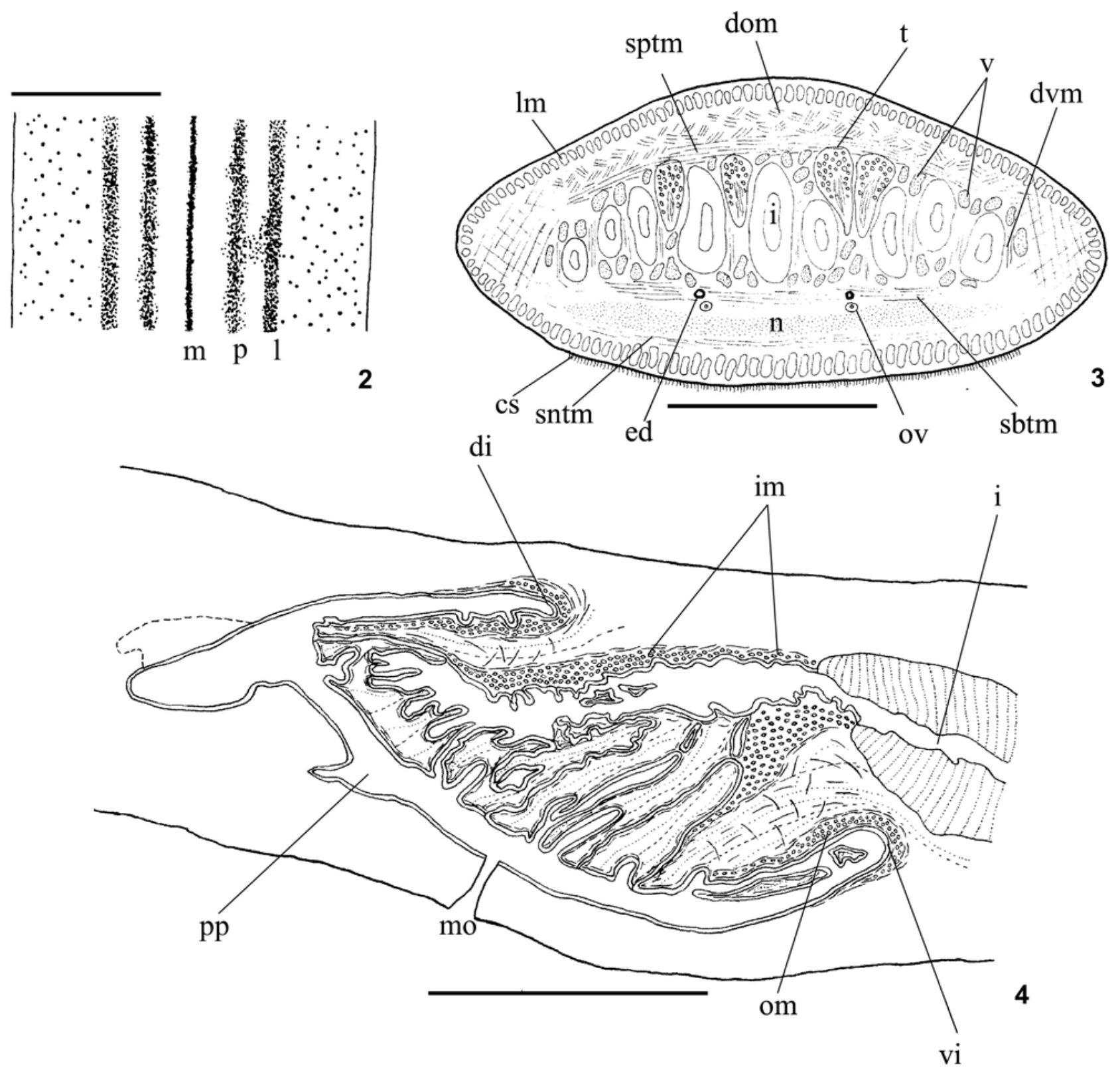

Figures 2-4. Notogynaphallia ceciliae sp. nov.: (2) paratype MZUSP PL.152, detail of the colour pattern of a preserved specimen; (3) paratype MZUSP PL.151, diagrammatic transverse section of the pre-pharyngeal region; (4) paratype MZUSP PL.151, diagrammatic sagittal section of the pharynx. (cs) Creeping sole, (di) dorsal insertion, (dom) dorsal subcutaneous oblique mesenchymatic muscle layer, $(\mathrm{dvm})$ dorso-ventral mesenchymatic muscle fibers, (ed) efferent ducts, (i) intestine, (im) internal musculature, (l) lateral stripe, ( $\mathrm{Im}$ ) longitudinal cutaneous muscle layer, $(\mathrm{m})$ median stripe, $(\mathrm{mo})$ mouth, $(\mathrm{n})$ nerve plate, $(\mathrm{om})$ outer musculature, (ov) oviducts, ( $\mathrm{p}$ ) paramedian stripe, (pp) pharyngeal pouch, (sbtm) subintestinal transversal mesenchymatic muscle layer, (sntm) subneural transversal mesenchymatic muscle layer, (sptm) supraintestinal transversal mesenchymatic muscle layer, (t) testes, (v) vitellaria, (vi) ventral insertion. Scale bar: $1 \mathrm{~mm}$.

section of the holotype. However, the greater height of the cutaneous musculature, specially on the venter, is not medially; more laterally it may be up to $7 \mathrm{~mm}$ higher dorsally and
$14 \mathrm{~mm}$ ventrally, in different specimens. Then it diminishes towards the margins of the section, there attaining its lowest height. Mc:h 14 to 17\% (Tab. II). 
Table I. Measurements (mm) of type-specimens of N. ceciliae sp. nov. (-) Not measured, $\left({ }^{*}\right)$ after fixation, (DG) distance of gonopore from anterior end, (DM) distance of mouth from anterior end, (DMG) distance between mouth and gonopore.

\begin{tabular}{|c|c|c|c|c|c|c|}
\hline Measurements & Holotype & $\begin{array}{c}\text { Paratype } \\
\text { MZUSP PL.151 } \\
\end{array}$ & $\begin{array}{c}\text { Paratype } \\
\text { MZUSP PL.152 } \\
\end{array}$ & $\begin{array}{c}\text { Paratype } \\
\text { MZU PL.00027 } \\
\end{array}$ & $\begin{array}{c}\text { Paratype } \\
\text { MZU PL.00028 } \\
\end{array}$ & $\begin{array}{c}\text { Paratype } \\
\text { MZU PL.00029 } \\
\end{array}$ \\
\hline Maximum length in extension & 36.0 & 63.0 & 35.0 & 35.0 & 38.0 & 55.0 \\
\hline Maximum width in extension & 2.5 & 3.0 & 1.0 & 2.5 & 2.0 & 2.5 \\
\hline Length at rest & - & - & 21.0 & 18.0 & 19.0 & 30.0 \\
\hline Maximum width at rest & - & - & 2.0 & 3.0 & 3.0 & 4.0 \\
\hline Length* & 35.0 & 38.0 & 26.0 & 23.0 & 27.0 & 36.0 \\
\hline Width* & 2.5 & 4.0 & 2.0 & 2.0 & 2.5 & 3.5 \\
\hline $\mathrm{DM}^{*}$ & 19.0 & 21.0 & 16.0 & 14.0 & 16.0 & 20.0 \\
\hline DM relative to body length (\%)* & 54.0 & 55.0 & 61.0 & 61.0 & 59.0 & 56.0 \\
\hline $\mathrm{DG}^{*}$ & 27.5 & 29.0 & 20.0 & 18.0 & 21.0 & 24.0 \\
\hline DG relative to body length $(\%)^{*}$ & 78.0 & 76.0 & 77.0 & 78.0 & 78.0 & 66.0 \\
\hline $\mathrm{DMG}^{*}$ & 8.5 & 8.0 & 4.0 & 4.0 & 5.0 & 4.0 \\
\hline Creeping sole (\%) & - & 75.0 & - & - & - & 85.0 \\
\hline Length of prostatic vesicle & 3.4 & 3.3 & - & - & 1.5 & 3.0 \\
\hline Length of male atrium & 3.70 & 3.00 & - & - & 0.17 & 3.20 \\
\hline Length of female atrium & 0.90 & 0.50 & - & - & 0.14 & 0.70 \\
\hline
\end{tabular}

Table II. Cutaneous musculature in the median region of a transversal section of the pre-pharyngeal region and ratio of the height of the cutaneous musculature to the height of the body (mc:h index) of type specimens of $N$. ceciliae sp. nov.

\begin{tabular}{lccc}
\hline & Holotype & $\begin{array}{c}\text { Paratype } \\
\text { MZUSP PL.151 }\end{array}$ & $\begin{array}{c}\text { Paratype } \\
\text { MZU PL.00028 }\end{array}$ \\
\hline Circular ventral & 3 & 3 & 2 \\
Oblique ventral & 17 & 19 & 13 \\
Longitudinal ventral & 90 & 74 & 60 \\
Ventral total & 110 & 96 & 75 \\
Circular dorsal & 3 & 3 & 2 \\
Oblique dorsal & 12 & 8 & 9 \\
Longitudinal dorsal & 59 & 69 & 54 \\
Dorsal total & 74 & 80 & 65 \\
mc:h (\%) & 16 & 14 & 17 \\
\hline
\end{tabular}

Mesenchymatic musculature (Fig. 3) of the type described by Froenlich (1955) for the genus Geoplana; well developed and with the four characteristic layers: dorsal subcutaneous with oblique fibers variously oriented; supra-intestinal transversal (7-10 fibers thick); sub-intestinal transversal (6-9 fibers thick); and subneural transversal (4-5 fibers thick). Very scattered oblique ventral subcutaneous fibers, also present. Oblique ventral subcutaneous fibers loosely arranged, also present. Margins of body with bundles of muscle fibers running obliquely from dorsum to venter, both on sagittal as well as on transverse planes. Dorsoventral fibers run almost vertically on body margins and between intestinal branches.

Pharynx (Fig. 4) bell-shaped with dorsal insertion and mouth, both approximately on the same transversal level, at the median third of the pharyngeal pouch; margins highly folded. Proximal part of the pharyngeal lumen communicates directly with the intestine, so that there is no esophagus. Pharyngeal glands with cell bodies located in the mesenchyme, mainly anteriorly to the pharynx. Two types of pharyngeal glands were distinguished: erythrophil secretory cells and cyanophil secretory cells, the latter with an amorphous secretion.

Outer musculature of the pharynx consisting of a thin longitudinal subepithelial layer (ca. $3 \mu \mathrm{m}$ ), followed by a circular one (ca. 71-75 $\mu \mathrm{m}$ ), having, mainly internally, some mixed longitudinal fibers. Towards the pharyngeal tip, the circular layer diminishes in thickness, becoming as thin as the longitudinal one. Inner pharyngeal musculature composed of a thick circular subepithelial layer (ca. 59-75 $\mu \mathrm{m}$ ), followed by a weak longitudinal one (ca. 7-9 $\mu \mathrm{m})$. Thickness of the inner musculature gradually diminishes outwards, and especially dorsally, also inwards, being greater at the level of the pharyngeal insertions.

Reproductive apparatus. Most anterior testes posterior to the ovaries, approximately at $11 \mathrm{~mm}$ and $12 \mathrm{~mm}$ from the anterior tip (30\% and $31 \%$ of the body length), respectively, in paratypes MZU PL.00029 and MZUSP PL.151; most posterior ones lateral to pharynx approximately at mouth level (54\% and $56 \%$ of the body length, respectively, in paratypes MZUSP PL.151 and MZU PL.00029). Testes in two irregular rows be- 

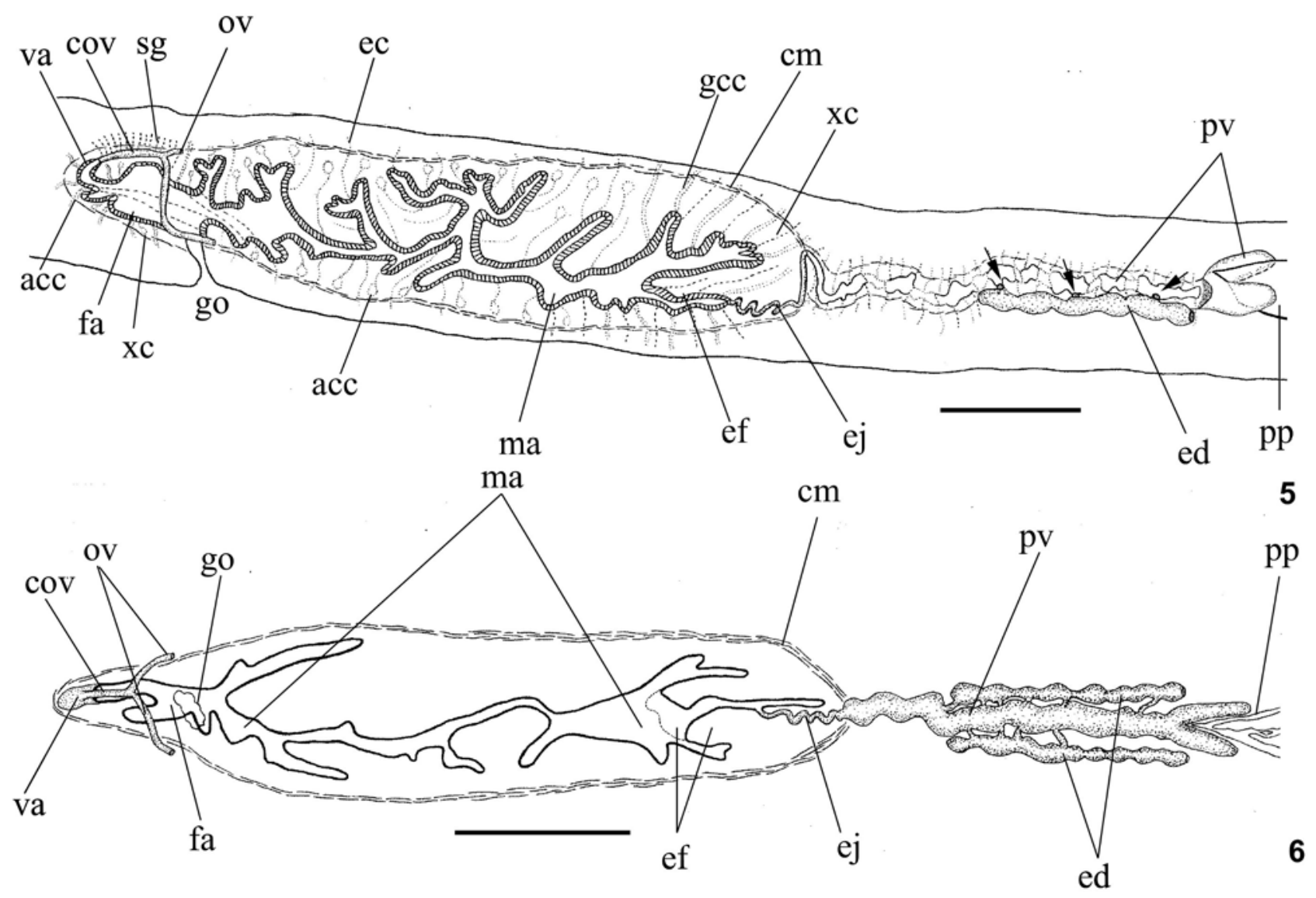

Figures 5-6. Notogynaphallia ceciliae sp. nov.: (5) holotype, diagrammatic saggital composite reconstruction of the copulatory apparatus; (6) paratype MZU PL.00029, diagrammatic horizontal composite reconstruction of the copulatory apparatus. (acc) Amorphous cyanophil secretory cells, $(\mathrm{cm})$ common muscular coat, (cov) common glandular oviduct, (ec) erythrophil secretory cells, (ed) efferent duct, (ef) ental fold, (ej) ejaculatory duct, (fa) female atrium, (gcc) granulous cyanophil secretory cells of proximal third, (go) gonopore, (ma) male atrium, (ov) oviducts, (pp) pharyngeal pouch, (pv) prostatic vesicle, (sg) shell glands, (va) vagina, (xc) xanthophil secretory cells. Arrows indicate openings of the efferent duct into the prostatic vesicle. Scale bar: $1 \mathrm{~mm}$.

neath the dorsal transversal mesenchymatic muscles dorsally and intersticially to the intestinal branches on each side of the body (Fig. 3). Efferent ducts dorsal to the oviducts, laterally displaced at intervals, and lined with a cuboidal epithelium. From the level of the pharynx, efferent ducts widen up forming the false seminal vesicles which, posteriorly to the pharynx, give off successive branches which open separately into the anterior, and especially into the median, third of the prostatic vesicle (Figs 5-6). Each efferent duct gives off 3 to 6 branches (Fig. 6).

Very long extrabulbar prostatic vesicle (Tab. I), laterally sinuous, with anterior end forked and continuing as a short branch on each side of the pharyngeal pouch (Figs 5-6). Lined with ciliated, tall columnar to pseudostratified epithelium, receiving the opening of numerous secreting cells with an erythrophil granulous secretion. Two cell types can be distinguished: (1) cells with fine secretory granules; and (2) cells with coarse secretory granules. Cell bodies of the two types are lo- cated around the vesicle or anteriorly to it. Muscularis of the prostatic vesicle (ca. $26 \mu \mathrm{m}$ thick) comprised of circular fibers, followed externally by longitudinal ones. Entering the muscle coat of the penis bulb, the prostatic vesicle, considerably narrowed, forms the ejaculatory duct which proceeds ventrally before taking a very sinuous directed path to open into the proximal end of the male atrium (Figs 5-8, 10). Both in paratypes MZUSP PL.151 and MZU PL.00029, opening of the ejaculatory duct displaced to the ventral proximal wall. Ejaculatory duct lined with a cuboidal to columnar ciliated epithelium, without secretory cells; muscularis (ca. $8 \mu \mathrm{m}$ thick) constituted of a circular subepithelial muscular layer, and some subjacent longitudinal fibers.

Male atrium folded and very long (Tab. I, Figs 5-10). Entally to the atrial wall, there is an extensive fold whose form, connections with the atrial walls and relative length are very variable among different specimens, especially in relation to the worm developmental stage. In the holotype and paratype

Revista Brasileira de Zoologia 20 (4): 745-753, dezembro 2003 
MZUSP PL.151 it projects into the atrial cavity dorsally to the entrance of the ejaculatory duct, occupying, respectively, ca. one-third and one-quarter of the atrial length. In paratype MZU PL.00028, still immature, the ental fold, coming from the right wall of the atrium, extends throughout more than half its length, above the ental ventral entrance of the ejaculatory duct, and joins here and there the dorsal and ventral atrial walls (Fig. 10). Male atrium lined with a non-ciliated, columnar epithelium, taller at its distal portion, showing a very irregular xanthophil apical cytoplasm. Portions of this cytoplasm are seen free in the atrial lumen. Distribution of the secretory cells indicates two distinct regions in the atrial surface. That of the proximal third receives two types of secretory cells, granulous cyanophil and granulous xanthophil, both types with cell bodies external to the common muscle coat of the genital apparatus. In the remaining surface two other types of secretory cells open. The most abundant one, with cell bodies internal to the muscle coat, are cyanophil cells with an amorphous secretion. The cells of the other type have an erythrophil granulous secretion and cell bodies external to the muscle coat. Thick atrial muscularis (ca. 78-92 $\mu \mathrm{m}$ ) comprised of circular and longitudinal interwoven fibers, circular ones subepithelially more abundant. In the neighbourhood of the ejaculatory duct, and extending through some distance of the ental atrial surface, the muscularis is in contrast thinner than in the rest of the atrial surface.

Ovaries of both paratypes MZUSP PL.151 and MZU PL.00029, at $10 \mathrm{~mm}$ from the anterior tip, respectively $26 \%$ and $27 \%$ of the body length; ovoid or oval-elongated in shape, measuring 0.3 to $0.6 \mathrm{~mm}$ anterior-posteriorly. Oviducts arise dorsally from the median third of the ovaries and run backwards, dorsally to the nerve plate. Immediately after the gonopore in the holotype, or laterally to it in paratype MZUSP PL.151, they rise and lead to the median saggital plane, uniting dorsally to the female atrium to form the common glandular oviduct.

Oviducts lined with a ciliated columnar epithelium, cells possessing basal nuclei and strong cyanophil cytoplasm; circular muscle fibers subepithelially. The ascending portion of the oviducts with larger diameter, stronger muscularis, and openings of shell glands in distal segment. Common glandular oviduct runs backward and inclines slightly ventrally before opening into the vagina (Fig. 5); lined with a ciliated, tall columnar epithelium whereon the shell glands open. Muscularis mainly comprised of circular fibers.

Vagina as a terminal dorso-anteriorly curved diverticulum of the female atrium (Figs 5, 8-10); lined with a non-ciliated pseudostratified columnar epithelium that receives secretory cells with a cyanophil amorphous secretion. Muscularis comprised of longitudinal and circular fibers.

Female atrium ample with folded walls, variable in length (Tab. I, Figs 5, 6, 8-10) from one-quarter to one-sixth of the male atrium length. In paratype MZUSP PL.151 (Fig. 8), very much contracted, the female atrium became restricted to an antero-posteriorly narrowed cavity continuing dorsally through the vagina and ventrally through the gonopore canal. In paratype MZU PL.00028 the female atrium is also very short, and oblique folds separate male and female cavities (Fig. 10). Female atrium lined with a non-ciliated tall columnar epithelium with xanthophil apical layer, receiving openings of two types of secretory cells; one, more numerous, with cyanophil amorphous secretion and cells bodies external to the muscle coat, and the second, more abundant near to the vagina, with coarse xanthophil secretion and subepithelially located cell bodies. Muscularis of the female atrium weakly developed, consisting of circular and longitudinal interwoven fibers.

At the level of the gonopore, there are two large folds that, together, partially separate male and female cavities (Figs $5,8-10)$. One projects from the dorsal wall, the other posteriorly from the anterior margin of the gonopore to the bottom of the female atrium, just beneath the exit of the vagina. Gonopore canal slightly inclined backwards (Figs 5, 9).

Common muscle coat (Figs 5-8) formed by longitudinal and circular fibers; thinner $(12 \mathrm{~mm})$ around the female atrium than around the male one $(15-22 \mathrm{~mm})$. Stroma between the common muscle coat and the muscularis highly muscularised with variously orientated fibers (Eigenmusculatur of Graff).

Remarks. The immature condition of paratype MZU PL.00028 is evident through its: small testes with no, or very few, spermatozoan in their lumina; thin incompletely developed efferent ducts that do not even reach the prostatic vesicle; short forked, almost straight tubular prostatic vesicle; short male atrium when compared to that of other specimens; indiscernible vitellaria and shell glands.

Vitellaria incompletely developed in holotype, and fully developed in paratypes MZUSP PL.151 and MZU PL.00029.

\section{DISCUSSION}

Although it is not the aim of the present work to make a thorough revision of the genus Notogynaphallia, it showed necessary to make some comments on the whole genus to simplify the discussion on N. ceciliae.

When Ogren \& Kawakatsu (1990) erected the genus Notogynaphallia for all Geoplaninae species without penial papilla, the male atrium with folded walls, and the female canal entering dorsally into the atrium, they tentatively gathered into it a rather heterogeneous array of species in relation to some other important characters of the reproductive organs or, in a few cases, characters other than those of the genital apparatus. Additionally, in some other cases, there was a misinterpretation of some structures, as it is easy to happen with regard to these animals when they are known exclusively through the literature, not always sufficiently clear.

In a first general approach to the genus, two groups of species can be distinguished:

Group 1 - species possessing a more diversified body shape and colour pattern than species in group 2. Some are slender, although seldom as slender as some of the species in group 2, with an almost homogeneous dark coloured dorsum, such as the type-species Notogynaphallia plumbea (Froehlich, 1956), or with a longitudinally striped dorsum, such as Notogynaphallia sexstriata (Graff, 1899), others being broader and flatter with a plain-coloured dorsum, such as Notogynaphallia garua (Bois-Reymond Marcus, 1951). The genital apparatus is more compact than in group 2, the prostatic vesicle being intrabulbar and communicating directly with the male atrium, without an intervening ejaculatory duct; the female atrium is small and, in most of the species, restricted to the female canal, which emerges from the common atrium just behind the gonopore. Besides of N. plumbea, N. sexstriata and N. garua, belong to group 1: N. albonigra (Riester, 1938), N.

Revista Brasileira de Zoologia 20 (4): 745-753, dezembro 2003 

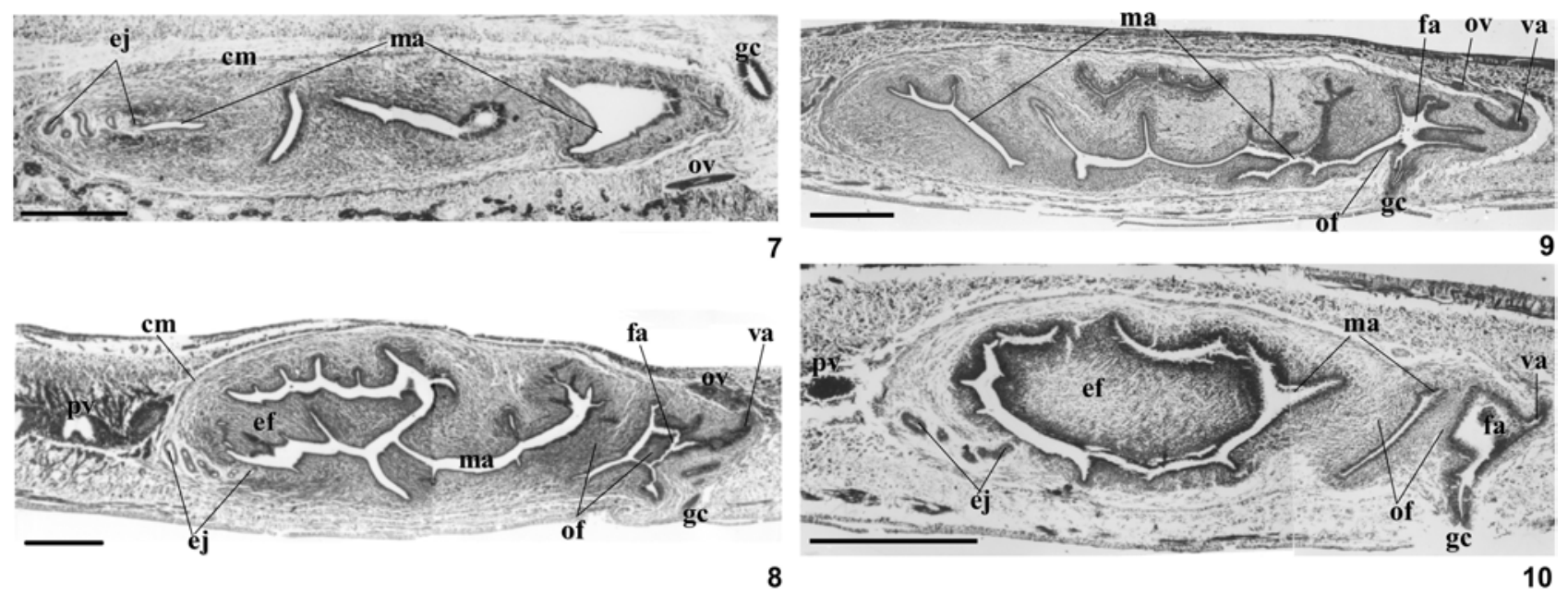

Figures 7-10. Copulatory apparatus of $N$. ceciliae sp. nov.: (7) horizontal section at the level of the opening of the ejaculatory duct (paratype MZU PL.00029); (8) sagittal section (paratype MZUSP PL.151); (9) para-sagittal section (holotype); (10) sagittal section (paratype MZU PL.00028). (cm) Common muscular coat, (ef) ental fold, (ej) ejaculatory duct, (fa) female atrium, (gc) gonopore canal, (ma) male atrium, (of) oblique folds, (ov) oviduct, (pv) prostatic vesicle, (va) vagina. Scale bar: $0.5 \mathrm{~mm}$.

parca (E.M. Froehlich, 1955), N. mourei (Froehlich, 1956) and N. froehlichae Ogren et Kawakatsu, 1990.

Group 2 - comprised by slender worms with longitudinal stripes on the dorsum (except for a single species with homogeneous coloured dorsum); a long genital apparatus, with an extrabulbar vesicle, and atria, especially the male one, with folded walls. The female atrium, although smaller than the male one, always with an ample variously pleated cavity plus the female canal. To this group, belong: $N$. ceciliae sp. nov.; Geoplana marginata (not Notogynaphallia marginata as in LEALZaNCHET \& FROEHLICH 2001) sensu Graff, 1899, Geoplana marginata (not Notogynaphallia marginata as in Leal-Zanchet \& Froehlich 2001) sensu Marcus (1951), Notogynaphallia abundans (Graff, 1899), Notogynaphallia muelleri (Diesing, 1861), Notogynaphallia caissara (E.M. Froehlich, 1955), Notogynaphallia fita and Notogynaphallia guaiana Leal-Zanchet \& Carbayo, 2001. The first four species constitute a complex of species with dark longitudinal stripes (Leal-Zanchet \& Froenlich 2001), and the last one, $N$. guaiana, is that single species without striped dorsum.

Furthermore, there are other species assigned to Notogynaphallia deserving some comments. $N$. bergi (Riester, 1938) has been recently transferred to a new genus by CARBAYO \& LEALZANCHET (2003), and proposed as its type-species. N. goetschi (Riester, 1938) must be transferred to another genus based on the presence of a permanent penial papilla (LEAL-ZANCHET \& CARBAYO 2001) and, especially, its peculiar mesenchymatic musculature (Froehlich's unpublished observation). N. tuxaua (E.M. Froehlich, 1955) and N. matuta (E.M. Froehlich, 1955) are two very similar species in relation to the genital anatomy, both presenting a well defined and constant penial papilla, although with some uncommon peculiarities. Thus, both species would be better allocated in the genus Geoplana. In fact they have already been transferred to Geoplana by LEAL-ZANCHET \& Carbayo (2001).

Notogynaphallia nataliae (Froehlich, 1959) shares some similarities with species of group 1 , such as the prostatic vesicle with the major part inside the bulb, and the female atrium almost reduced to the vagina or female canal. The male atrium, however, is long with some large ental folds. N. atra (Schultze \& Müller, 1857) is a small slender species sharing anatomical features with the species of group 2. However, the copulatory apparatus is rather compact and the globose prostatic vesicle is directed ventrodorsad close to the penis bulb. $N$. andina (Hyman, 1962) presents some very peculiar characteristics of the copulatory apparatus, which render its assignment to Notogynaphallia doubtful. In this species, the ejaculatory duct enters dorsally into the atrial wall, and the ample female cavity is obliquely oriented to the dorsum contrary to the great majority of the species of Geoplaninae which have it horizontally placed. HyMAN (1962) further described the genital apparatus as being "... not set off from the surrounding mesenchyme" and the eyes as not crossing the anterior tip. However, these characteristics, that could be mentioned here as distinctive from those of $N$. ceciliae, were not confirmed by Carbayo (pers. comm.), who is now studying the original material. These three last-commented species, have, each of them, a particular combination of characteristics which precludes their insertion into each of the two above delimited groups, as well as their gathering into a third one.

Finishing this list, OgRen \& KaWAKatsu (1990) tentatively assigned to Notogynaphallia two additional species, N. modesta (Graff, 1899) and N. quinquestriata (Hyman, 1962), which are known exclusively through their external morphology; both with a longitudinally striped dorsum: four and five striped, respectively.

In view of the above comments, $N$. ceciliae will be compared exclusively to species of group 2 , as well as with $N$. quinquestriata. However, the comparison of $N$. ceciliae with the three other species, constituting with it the species complex above mentioned, must wait for the redescription of these three

Revista Brasileira de Zoologia 20 (4): 745-753, dezembro 2003 
species in a future paper, when all of them will be discussed together.

Regarding the external morphology, two of the four remaining species of group 2 are readily separable from N. ceciliae. $N$. fita is a very long slender species with five longitudinal stripes on the cephalic region and four stripes along the major part of the body. Furthermore, in N. fita, the eyes do not spread dorsally as in $N$. ceciliae, instead, they are uniserially marginal throughout the whole body length. N. muelleri may occur syntopically as worms with three or one longitudinal stripe, the two forms being originally described as different species. It is also longer and more slender than $N$. ceciliae, although not so much as N. fita.

Notogynaphallia caissara possess five dark longitudinal stripes dorsally as in $N$. ceciliae. However, in $N$. ceciliae the arrangement of stripes relative to the body width is different: the five stripes are closer to each others and run nearer to the median dorsal line, leaving a wide band of the ground-colour on the margins. The median stripe is the thinnest one, the paramedian and lateral ones have a similar width. In $N$. caissara the stripes are equally distributed throughout the dorsal width, the lateral ones are the widest and the median one the thinnest. In addition, until now $N$. caissara is known exclusively from the state of Rio de Janeiro and the northern litoral of São Paulo state.

Notogynaphallia guaiana stands apart in group 2 by its homogeneously greyish-olive dorsum. In addition, it differs from $N$. ceciliae by having the eyes arranged in a marginal row. Finally, N. guaiana is a longer species, attaining, when crawling, more than twice $(145 \mathrm{~mm})$ the length of $N$. ceciliae $(63 \mathrm{~mm})$.

Except for $N$. fita and N. guaiana, all the species of group 2 have eyes spread dorsally in at least some portion of the body between the anterior end and the pharynx. Eyes exclusively in a marginal series also occur among species of group 1, such as $N$. sexstriata and $N$. plumbea, this evidencing that their distribution and the genital anatomy are independent characters.

Notogynaphallia quinquestriata, which also possess five stripes as the specific name denotes, was described by HyMAN (1962) based on a single worm, a juvenile, despite its size being comparable to that of mature specimens of $N$. ceciliae and $N$. caissara. The species is characterised by presenting dark marginal stripes instead of lateral ones as in the two latter species. These marginal stripes, surrounding the whole body, the extremities included, are the widest ones, and in contrast much fainter, rather grey, than the median and paramedian ones. The eyes do not surpass the limits of the marginal stripes but are not uniserial. Regarding the body shape, N. quinquestriata seems to be a relatively wider species. Although the possibility of its conspecificity with $N$. ceciliae cannot be definitely dismissed, as its anatomy is not known, this is rather unlikely considering, besides the characteristics discussed above, its distribution, Barro Colorado Island, Panama. According to our experience, Geoplaninae species exhibit a high degree of endemicity due to their poor capacity of locomotion through long distances, and, very probably, their specific environmental requirements as well. Additionally, the allocation of this species to Notogynaphallia must be taken as a tentative one, albeit it would be better to include it among the species gathered by Ogren \& Kawakatsu (1990) under Pseudogeoplana.

Notogynaphallia ceciliae is easily recognised as belonging to Notogynaphallia by the morphology of its genital apparatus, which is concordant with all characters defining the genus. By its efferent ducts being distally branched, each branch opening separately into the prostatic vesicle, $N$. ceciliae is also easily identified and separated, not only from the above considered four species of the same group, but also from all species assigned to Notogynaphallia and all Geoplaninae species. In fact, this is a very rare trait among the Terricola, as far as is known, the only other case in the literature refers to a species of the family Bipaliidae, viz.: Bipalium moseleyi Loman, 1887. The genital apparatus of this species was first described by BEAUCHAMP (1925), who wrote: "L'appareil copulateur, (...), est caractérisé par l'énorme développement de la vésicule séminale cylindrique, (...), et dans laquelle, fait unique à ma connaissance chez les Triclades, les cannaux déférents ramifiés débouchent de chaque côté par 7 à 9 orifices distincts."

\section{ACKNOWLEDGEMENTS}

To Dr. Fernando Carbayo and Dr. Fernando Marques for their constructive comments and suggestions on an early draft of the manuscript. To the Fundação de Amparo à Pesquisa do Rio Grande do Sul (FAPERGS) for travel grants given to AMLZ (APC 00/1888.3) and financial support to an integrated research project $(97 / 0538.6)$. Thanks are also due to the laboratorial technician Letícia A. Guterres for sections preparation and Teresinha H. Oliveira for photographic work, as well as to all who collaborated with the collecting of specimens.

\section{REFERENCES}

Beauchamp, P. DE. 1925. Quelques triclades terrestres de Bornéo. Archives de Zoologie expérimentale et générale, Paris, 64 (3): 63-70.

Carbayo, F. \& A.M. Leal-Zanchet. 2003. Two new genera and species of Geoplaninae (Terricola: Tricladida: Platyhelminthes) of Brazil in the light of cephalic specialisations. Invertebrate Systematics, Collingwood, 17 (3): 449-468.

Carbayo, F.; A.M. Leal-Zanchet \& E.M. Vieira. 2001. Land planarians (Platyhelminthes: Tricladida: Terricola) as indicators of man-induced disturbance in a South Brazilian rainforest. Belgian Journal of Zoology, Bruxelas, 131 (Suppl.): 223-224.

. 2002. Terrestrial flatworm (Platyhelminthes: Tricladida: Terricola) diversity vs. man-induced disturbance in an ombrophilous forest from Southern Brazil. Biodiversity and Conservation, Dordrecht, 11: 1091-1104.

Froenlich, C.G. 1955. Sobre morfologia e taxonomia das Geoplanidae. Boletim da Faculdade de Filosofia, Ciências e Letras da Universidade de São Paulo, São Paulo, série Zoologia, 19: 195-279.

Froenlich, E.M. 1955. Sôbre espécies brasileiras do gênero Geoplana. Boletim da Faculdade de Filosofia, Ciências e Letras da Universidade de São Paulo, São Paulo, série Zoologia, 19: 289-369.

Hyman, L. 1962. Some land planarians from Caribbean countries. American Museum Novitates, New York, 2110: $1-25$.

Leal-Zanchet, A.M. \& F. Carbayo. 2000. Fauna de planárias terrestres (Platyhelminthes, Tricladida, Terricola) da Floresta Nacional de São Francisco de Paula, RS, Brasil: uma análise preliminar. Acta Biologica Leopoldensia, São Leopoldo, 
22 (1): 19-25.

.2001. Two new species of Geoplanidae (Platyhelminthes, Tricladida, Terricola) from Brazil. Journal of Zoology, London, 253: 433-446.

Leal-Zanchet, A.M. \& E.M. Froehlich. 2001. A species complex in the genus Notogynaphallia (Tricladida: Terricola). Belgian Journal of Zoology, Bruxelas, 131 (Suppl.): 225-226.

Marcus, E. 1951. Turbellaria brasileiros (9). Boletim da Facul- dade de Filosofia, Ciências e Letras da Universidade de São Paulo, São Paulo, série Zoologia, 16: 5-215.

Ogren, R.E. \& M. Kawakatsu. 1990. Index to the species of the family Geoplanidae (Turbellaria, Tricladida, Terricola). Part I: Geoplaninae. Bulletin of the Fuji Women's College, Sapporo, 28: 79-166.

RomeIs, B. 1989. Mikroskopische Technik. München, Urban und Schwarzenberg, 697p.

Received in 17.VI.2003; accepted in 18.XI.2003. 